\title{
Effect of Methanolic Extract of Phoenix dactylifera L. Seeds (PDS) on Blood Glucose levels of Normoglycemic and Dexamethasone induced Diabetic Rabbits
}

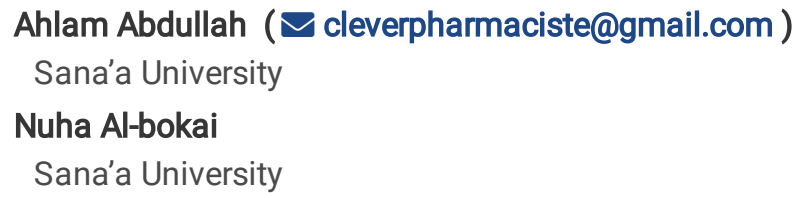

\section{Research Article}

Keywords: Phoenix dactylifera L., Diabetic Mellitus, fatty acids, flavonoids, insulin, Dexamethasone, Fasting blood glucose, PDS

Posted Date: March 8th, 2022

DOl: https://doi.org/10.21203/rs.3.rs-1400576/v2

License: @ (i) This work is licensed under a Creative Commons Attribution 4.0 International License. Read Full License 


\section{Abstract}

Background: The seeds of the date palm have also been shown to have nutritional and therapeutic properties. Plants are the source of many pharmaceutical compounds, so herbal treatments are attractive. In folk medicine, date seeds are commonly used to treat diabetes. Therefore, this study aimed to evaluate anti-diabetic potential of the methanolic extract of date palm seed (PDS) in dexamethasone (DMTZ) -induced diabetic rabbits.

Materials and Methods: The intraperitoneal injection of Dexamethasone (DMTZ) (150 mg/kg), experimental diabetes was induced in 42 male rabbits. The rabbits were divided into seven groups and administered the following treatments orally for 30 days: normal control (no treatment), placebo group, diabetic (no treatment), diabetic with PDS extract ( $200 \mathrm{mg} / \mathrm{kg} / \mathrm{day}$, P.0), diabetic with PDS extract (400 mg/kg/day, P.O), diabetic with PDS extract (400 mg/kg/day, P.O) with insulin (2UI/ kg B.Wt.), and diabetic with insulin (2Ul/ kg B.Wt.). Histopathological examination of the pancreas was performed. The results are expressed as mean \pm SD and variations of some animals were compared in the using of one-way ANOVA. Statistical significance was set at $P \leq 0.05$. Statistical evaluation was performed using Microsoft Excel, and SPSS software version.

Results: The methanolic PDS extract has been shown to have a significant anti-diabetic effect $(P \leq 0.05)$. This effect may be due to the presence of flavonoids, saponins and fatty acids in the extract, which could function through different mechanisms. Furthermore, pancreas tissue regeneration was histologically clean. However, further research is needed to isolate and elucidate the bioactive compound(s) responsible for its anti-diabetic properties, as well as its molecular mechanism of action.

Conclusion: This study suggests the anti-diabetic potential of date palm seed extract, which might be due to its hypoglycemic properties.

\section{Introduction}

Phoenix is the surname of seventeen palm species (canariensis, dactylifera, reclinata, sabal, rupicola. . .etc.) which a member of the palmate family ${ }^{1}$. For many people living in Yemen and other dry areas of the world, the feather palm (Phoenix dactylifera L.) plays a significant social, environmental, and economic role. The fruits of the feather palm are widely consumed in many parts of the world and are considered a major part of the diet and a staple food in most Arab countries, The seeds of Phoenix dactylifera $L$. (Arecaceae) have been found to contain a wide range of inhibitors. ${ }^{2}$ Many studies have examined the chemical composition of $P$. dactylifera seeds, revealing the existence of large amounts of phenolics, flavonoids, and amino acids, all of which are responsible for radical scavenging and medicinal operation $3,4,5$. According to a recent phytochemical study, the flavonoid content in $P$. dactylifera seeds is rutin and quercetin and, which are increased by preparation. ${ }^{6}$ Phoenix dactylifera $L$. (date palm) is a plant used in folk medicine to treat a variety of diseases and disorders, Dates and its constituents act as potent inhibitors, medicinal drugs, and antitumoral agents and provide an appropriate variety of medical aids in the treatment of various diseases. ${ }^{7}$

Diabetes may be a significant pathological condition, affects one-fifth of the world's population. Diabetes mellitus is a multietiological condition characterized by chronic symptoms, ${ }^{8}$ due to insufficient insulin hormone production or cells that do not respond to the hormones produced ${ }^{9}$. It is a condition in which the body produces insufficient insulin, stops producing insulin, or becomes increasingly resistant to its activity ${ }^{10}$. In patients with the polygenic condition, effective glucose control is the key to preventing diabetic complications and improving quality of life. ${ }^{27}$, The ability of insulin hormone to mediate tissue glucose uptake may be a critical step in preserving the physiological state of glucose and clearing the postprandial glucose load. ${ }^{11,12}$ In 2019,463 million people worldwide have diabetes, accounting for $9.3 \%$ of the global population, with $80 \%$ of those living in low and middle-income nations. According to estimates, 2045,700 million people will make up 10.9 percent of the global population. ${ }^{13,14}$

Diabetes mellitus can cause symptoms such as thirst, polyuria, blurred vision, and weight loss. Several pathogenic processes are involved in the development of polygenic disorders. With sequential hormone deficiency, represents processes that destroy pancreatic beta cells. Abnormalities in sugar, fat, and macromolecule metabolism are caused by a lack of hormone action on course tissues as a result of hormone inability or lack. ${ }^{8}$

For a long time, diabetes has been treated using a variety of medicinal plants, with medicinal plant extracts being reported to improve diabetic control while reducing related adverse effects when compared to synthetic medications. ${ }^{15}$ 
Dexamethasone is a sex hormone. Steroids increase glucose levels in three ways: they block the action of insulin, which causes hormone resistance, and less glucose is ready to move out of the blood to be concerned by the muscles. This causes the liver to release additional glucose into the blood, resulting in a high glucose level ${ }^{16}$. Dexamethasone use utilize to improve analgesia and reduce the incidence of nausea and vomiting. Dexamethasone, on the other hand, has the potential to raise blood glucose levels, which is a known risk factor for problems ${ }^{17}$. The hypoglycemic effects of various components of various palm species have been reported in some studies.

In a recent study, the liquid extract of $P$. dactylifera $L$. seeds was found to be capable of stimulating endogenous hormone secretion through additional sources, which may be the mechanism of its hypoglycemic action. ${ }^{11}$ Another study found that a fruit extract of $P$. dactylifera has a protective effect against diabetic pathology in rats ${ }^{12}$. Many indigenous medicinal herbs and extracts from various sections of these plants such as roots, shoots, and seeds. have been used in the management of diabetes ${ }^{18}$ due of the different active phytochemicals present in these plants.

However, the goal of this research was to assess the possibility of using the date palm seed as an anti-diabetic agent in nondiabetic and diabetic rabbits induced by dexamethasone; the Methanolic extract of the seed had a hypoglycemic effect.

\section{Materials \& Methods}

\subsection{Plant material}

The seeds were obtained from Albalh Dates collected in Tehama / Alhodidah, Yemen, from the fruits of Phoenix dactylifera L. (Arecaceae), The plant was identified by Dr. Zamila Ahmed, Demonstrator at the Faculty of Science Department of Plants, Sana'a University, Sana'a, Yemen. The seeds were sun-dried before being roasted at $40 \%$ and then ground to a fine powder by gender.

\subsection{Preparation of methanolic crude extract (whole product)}

\subsubsection{Maceration}

The seeds of PDS were collected from Tehama in Yemen

30 kilograms of Phoenix dactylifera L. fruit were removed from the seeds and washed thoroughly with distilled water before being dried by the sun and roasted in an oven (Memmert, Model; SFE600, Schwabach, Germany), at 40-50 C for $4 \mathrm{~h}$. They were then pulverized into a fine powder using a grinder (Taizhou Jincheng Pharmaceutical Machinery Co., Ltd., Model; SF, Jiangsu, China), and soaked in $99.9 \%$ methanol $(\mathrm{W} / \mathrm{V})$ at room temperature $\left(25 \mathrm{C}^{\circ}\right)$ for 4 weeks and shaken several times with shaker equipment (GFL 3017 Shaker, Serial No. 103488051, Germany), (maceration method). The extract-containing methanol was filtered with gauze followed by Whatman filter (Whatman, Buckinghamshire, England), and the residue was combined with methanol at a ratio of (W/V). The filtrate was vacuum distilled at $40{ }^{\circ} \mathrm{C}$ in a rotary evaporator (Buchi rotavapour R-200 equipped with buchi heating bath B-490, buchi vacuum controller V-800, Germany). The final extract was a red semi-solid with a dry weight of $90 \%$ weighed by balance (Electronic balance, APEX-100, Denver instrument, Germany). This methanol extract (as a whole product).19

\subsubsection{Fractionation}

The overall semi-solid of the complete product of the methanolic extract was placed in a separating funnel, shaken, and allowed to stand for minutes before collecting the benzene layer in an excess beaker. When using $250 \mathrm{cc}$ of aromatic hydrocarbons, the procedure repeated twice. Starting with Hexane, pet. Ether, chloroform, Ethyl acetate, and distal water, the previous step was repeated with entirely different solvents wherever possible. On 9 extracts the following fraction was obtained: (Benzene; Hexane; pet. Ether; chloroform; oily; emulsion; ethyl acetate; aqueous; and methanol).

2.2.3. Preliminary phytochemical screening

Page $3 / 11$ 
A preliminary phytochemical analysis of the plant extract was carried out by using Thin Layer Chromatography (T.L.C) plates coated with silica gel 60 F254 for T.L.C. The mobile phase Ethyl acetate: Methanol (9.5:0.5) was added to the chromato-tank and left for a time to saturate the tank; micro-drops of the concentrated solutions of the fractions obtained (benzene, hexane, petroleum ether, chloroform, oily, emulsion, ethyl acetate, aqueous and methanol extracts) were spotted on pre-coated Silica gel. The chromatogram after complete development was air dried and visualized with different chemical reagents.

\subsection{Experimental animals}

Male rabbits weighing $0.77-1.5 \mathrm{~kg}$ are healthy. They were collected from the animal house of the Faculty of Science, Sana'a University. The Animal Ethics committee, Government of Yemen constituted, Sana'a University, accepted the current study before the start of the experiment. The animals were held in standard polypropylene cages with a 12:12 hour light/dark cycle and under controlled temperature $\left(25 \pm 2{ }^{\circ} \mathrm{C}\right)$ and kept at the same room temperature and humidity. Before beginning the experiment, all the rabbits were given a 14-day acclimatization period.

\subsection{Acute toxicity study}

Mal rabbits randomly divided into three groups of three rabbit per group. Group one was the untreated control rabbit. Group two was given 1-2 $\mathrm{ml}$ of distal water, which was used as a placebo control. Group three included rabbits treated with a single oral dose of $5,000 \mathrm{mg} / \mathrm{kg}$ extract. acute toxicity testing according to the Organization for Economic Cooperation and Development's (OECD) updated up-and-down protocol21. Before the start of the experiment, rabbits were fasted from food but not water for the night before the extract was given orally. Based on the individual animal body weights obtained on the day of dosing of the acute toxicity study doses $(1,000,2,000,3,000,4,000$, to $5,000 \mathrm{mg} / \mathrm{kg}$ b.w.), was dissolved in distilled water at an administration volume of $10 \mathrm{ml} / \mathrm{kg}$ body weight and given to the first rabbit by oral gavages, then hourly for 3 hours, and finally regularly until 48 hours. For 14 days, all the experimental animals were kept under close observation, and the number of rabbits that did not die during the study period was recorded. Toxicity in the short term, no mortality was observed at the end of the experiment after a single dose oral administration of PDS extract to rabbits up to a dose of $(5,000 \mathrm{mg} / \mathrm{kg})$.

\subsection{Induction of diabetes}

A single dose of dexamethasone $(150 \mathrm{mg} / \mathrm{kg})$ was administered intraperitoneally to induce diabetes.22Male rabbits fasted an 18hour. Blood from the rabbits' hearts was used to assess their fasting blood sugar (FBS) levels before being injected with dexamethasone. To induce hyperglycemia, freshly prepared dexamethasone was dissolved in normal saline $(0.9 \% \mathrm{~W} / \mathrm{v} \mathrm{NaCl})$ and injected intraperitoneally as a single dose of $150 \mathrm{mg} / \mathrm{kg}$. Rabbits were held on $5 \%$ glucose for the next 24 hours to prevent fatal hypoglycemia caused by major pancreatic insulin release.22 Rabbits with a fasting blood glucose level of more than $250 \mathrm{mg} / \mathrm{DL}$ after 72 hours were considered as diabetic. The experiment was approved by the Institutional Ethical Committee, Faculty of Pharmacy, Sana`a University.

\subsection{Experimental design Evaluation of Antidiabetic activity of PDS methanolic extract in dexamethasone-induced diabetic}

Rabbits divided into two major groups as shown in Diagram No (A-1). After 72 hours from the administration of dexamethasone to rabbits with hyperglycemia, more than $250 \mathrm{mg} \backslash \mathrm{dl}$ was selected and is used for the experiment. The rabbits were administered the extract (dissolved in normal saline from 1-2 ml) for two weeks orally by using a feeding cannula. For the experimental rabbits, FBG was estimated before the start of treatment, on one week and two weeks, and 30 days of treatment. All rabbits were later sacrificed on 30 th days by diethyl ether and the Pancreases were collected in $20 \%$ formalin for histopathological examination.

\subsection{Histopathological examination of Pancreas}

For the histological study, specimens of pancreases were immersed in neutral buffered formalin (10\%) for 48 hours. A routine method of dehydration in ascending series of ethanol, followed by tissue clearing using, clearing with xylene and embedding in paraffin was used. Sections of 5- $\mu \mathrm{m}$ thickness were sliced using a microtome and were stained with Hematoxylin and Eosin stain23.

\subsection{Histopathological studies}

Tissue samples of the pancreas were fixed in $10 \%$ buffered formalin and were processed for histopathological examination. A routine method of dehydration in ascending series of ethanol, clearing with xylene, and embedding in paraffin was used. Sections of

Page $4 / 11$ 
$5-\mu \mathrm{m}$ thickness were sliced using a microtome and were stained with Hematoxylin and Eosin stain.23

\subsection{Statistical analysis}

The results were expressed as mean \pm SD and differences among the groups of animals were compared using one-way ANOVA with posthoc LSD's test. Statistical significance was set at $P \leq 0.05$. Statistical analysis was performed using Microsoft Excel, and SPSS software version.

\section{Results}

\subsection{Phytochemical analysis and acute toxicity assessment}

A phytochemical screening of the PDS (Table. 1) revealed the existence of steroids, amino acids, lipids, fatty acids, flavonoids, phenols, anthraquinone and saponins., were abundant in the extract.

\section{Acute toxicity test results}

Physical and behavioral tests were used to determine the acute toxicity of a methanolic extract (crude product) of phoenix dactylifera L. seeds. During the 14-day observation period, administration of the extract with a single oral dose of $5000 \mathrm{mg} / \mathrm{kg}$ did not result in mortality. During the experiment, no general behavior, physiological activities, or signs of toxicity were observed, such as changes in the color of the eyes, and urine, abnormal secretion, nausea, diarrhea, sleep, or hair erection.

\subsection{Hypoglycemic activity of PDS in non-diabetic rabbits}

The extract at $200 \mathrm{mg} / \mathrm{kg}$ showed significant hypoglycemic activity in non-induced hyperglycemic rabbits (P < 0.05), with groups $(3,4,5,6)$ with the extracts of the whole product, aqueous, methanol, and emulsion showing a decrease in blood glucose and with oily extract group (7) showing an increase in blood glucose in non-diabetic rabbits, as shown in Table (2).

\subsection{Hypoglycemic activity of PDS and its extracts upon subacute administration in dexamethasone-induced diabetic rabbits}

As shown in the FIG. (1): The methanol extract of PDS has hypoglycemic activity in dexamethasone-induced diabetic rabbits when given subacutely. Methanol extract at $200 \mathrm{mg} / \mathrm{kg}$ had a significant antidiabetic effect from the 1st week onwards (P < 0.05$)$ fig (c). And Methanol extract at $400 \mathrm{mg} / \mathrm{kg}$ had a significant antidiabetic effect from the 2 nd week onwards ( $<<0.05)$, fig (D). Nevertheless, the administration of the extract at $200 \mathrm{mg} / \mathrm{kg}$ had an antidiabetic effect. In diabetic rabbits, dose-dependent antidiabetic activity experiments revealed that the extract had a remarkable hypoglycemic effect at $400 \mathrm{mg} / \mathrm{kg}(P<0.05)$. As shown in Table $(3)$. Methanol extract in two doses, $200 \mathrm{mg} / \mathrm{kg}$ and $400 \mathrm{mg} / \mathrm{kg}$ had a hypoglycemic effect $(P<0.05)$, at $400 \mathrm{mg} / \mathrm{kg}$ being the most effective in lowering glucose levels (Table 3) Figure (C, D). Administration of insulin at $2 \mathrm{Ul} / \mathrm{kg}$ had an anti-diabetic effect in fig(E); however, when insulin $2 \mathrm{Ul} / \mathrm{kg}$ was combined with methanol extract $400 \mathrm{mg} / \mathrm{kg}$, there was a greater reduction in blood sugar as shown in fig(F).

\section{Discussion}

The anti-diabetic potential of $P$. dactylifera seeds $P D S$ extract were evaluated by assessing its hypoglycemic activity in dexamethasone-induced diabetic rabbits. In the present study, treatment with PDS and its extracts had a significant antihyperglycaemic effect. The phytochemical and nutritional contents of the PDS have the most abundant fatty acids in date seed oils, were oleic, lauric, myristic, palmitic, and linoleic acids. Date seeds had phenolic and flavonoid content, saponin, steroids, amino acids, phenols respectively. Date seeds could be employed as components to boost the nutritional value of various functional foods for human consumption, as well as used as food, medicinal, and cosmetic additives, according to the findings ${ }^{24}, 25$. The acute toxicity of the substance was investigated up to a high concentration of $5,000 \mathrm{mg} / \mathrm{kg}$ b.w. (20 times more than the therapeutic dose), The extract showed no signs of toxicity even at this level. The main goal of preliminary acute toxicity research is to get a sense of whether there would be noticeable behavioral abnormalities or mortality, and PDS did not show any toxic signs in this limited toxicity test in male rabbits. According to a survey of the literature, no studies on this plant's other pharmacological qualities or phytochemistry have been conducted. Dexamethasone are known to increase blood glucose levels by stimulating hepatic gluconeogenesis and increasing insulin resistance 22,26 . In animal investigations, Dexamethasone administration has been shown to 
cause insulin resistance and hyperglycemia. When the dose of dexamethasone $150 \mathrm{mg} / \mathrm{kg}$ was given, the hyperglycemic impact of Dexamethasone was potentiated/aggravated, according to our findings ${ }^{27}$. Dexamethasone can produce rise in blood glucose levels by stimulating hepatic gluconeogenesis and increasing insulin resistance. ${ }^{17}$

They also stimulate the liver to release additional glucose into the bloodstream. Although date palm seeds PDS have long been used in traditional medicine to treat diabetes, few studies have looked at their anti-diabetic properties. Previous research has shown that when paired with insulin, the aq PDS improves glycemic control in diabetic rats compared to insulin alone, and this effect could be attributed to the stimulation of insulin production ${ }^{11}$.

\section{The hypoglycemic effect of Phoenix dactylifera $L$ seeds extracts may be due to one or more of the following mechanisms: -}

1. It may be able to imitate the actions of insulin may have a mode of action similar to hypoglycemic insulin, which promotes insulin production by closing K+-ATP (adenosine 5-triphosphate) channels. This causes membrane depolarization and an increase in $\mathrm{Ca} 2+$ influx, and it is an important first step in insulin secretion.

2. Normal beta-cell function for glucose-fatty acid cross-talk in insulin secretion control to induce insulin production, glucose must first enter the beta cell via a glucose transporter and then be digested to a level higher than pyruvate in a process started by the high enzyme glucokinase. This, in turn, is hypothesized to result in an increase in the ATP:ADP ratio as show in diagram (1), cell depolarization, and opening of the voltage-sensitive Ca2 channels, resulting in an increase in intracellular [Ca2+] and activation of exocytosis, Additional pathways, on the other hand, contribute to insulin secretion regulation throughout the whole animal. The K+ ATP channel-independent pathway, for example, enhances the response to a higher [Ca2+] generated by the more traditional method. A second mechanism of glucose signaling, known as the K+ ATP channel-independent, Ca2+-independent pathway, appears to entail a GTP-dependent step that is activated by the combined activities of protein kinase A (PKA) and protein kinase C. (PKC). ${ }^{28}$ Several additional plants have been shown to have antihyperglycaemic and insulin-stimulatory properties in this setting.

3. Tissue sensitivity to available nutrients has increased. further, this antidiabetic activity indicates that Phoenix dactylifera L. may stimulate insulin secretion from the remaining $\beta$-cells or regenerated $\beta$-cells this effect may be due to the effect of saponin which exerts its hypoglycemic effect, which exerts its hypoglycemic effect. An extra-pancreatic mechanism includes increased insulinreceptorbinding, and increases transmembrane passage of glucose across cells membranes of most body cell, which promotes the conversion of glucose to glycogen through induction of glucokinase and glycogen synthase ${ }^{29}$.

4. It may be due to the effect of active fatty and amino acids, flavonoids, phenols, and steroids; these compounds may scavenge free radicals liberated by dexamethasone in diabetic rabbits ${ }^{27}$. Insulin is involved in the metabolism of lipids as well as the regulation of carbohydrate metabolism. Insulin reduces the activity of hormone-sensitive lipases in adipose tissue and reduces the release of free fatty acids, making it a strong lipolysis inhibitor. This enzyme's activity is increased in diabetes, which enhances lipolysis and releases more free fatty acids into circulation. The extract and its components appear to exhibit insulinlike activity, according to our findings. In diabetics, higher fatty acid concentrations increased fatty acid -oxidation, resulting in more acetyl-CoAand cholesterol. Some plants with flavonoids and fatty acids, as well as steroids, have been shown to have hypoglycemic effects. ${ }^{30,31}$ The mechanism of action of the PDS extract's anti-diabetic activities is unknown. However, phytochemical elements such as flavonoids, fatty, and amino acids, tannins, steroids, and others are likely to be returned. These compounds are derived from a variety of plant sources and be effective hypoglycemic agents ${ }^{32}$. Numerous studies have found flavonoids to have anti-diabetic, anti-hyperlipidemic, and antioxidant properties $33,34,35$. Flavonoids can lower blood glucose levels through both pancreatic and extra pancreatic pathways. In vitro and in vivo systems, they can serve as insulin secretagogues, increasing insulin secretion 36,37 . They can also lower glucose absorption by inhibiting -glucosidase activity in the intestine ${ }^{38}$. The presence of fatty acids in the seeds may play a role in lowering blood sugar levels by inducing insulin release from pancreatic cells, as show in the diagram no. (1). Diabetes, a disease in which glucose and lipid metabolism are inadequately regulated by insulin, is a severe global health issue 8,9 . Insulin is released by pancreatic cells in response to high blood glucose levels, and its release is influenced by a variety of factors ${ }^{13}$. Free fatty acids (FFAs) are a significant source of energy as well as signaling molecules in a variety of physiological functions, including insulin secretion ${ }^{39}, 40$. Increased levels of free fatty acids [FFA] have been associated to insulin resistance and cell malfunction. However, believing that decreased glucose absorption in muscle is attributable to increased fatty acid oxidation and decreased glucose oxidation ${ }^{27}$. FFAs are thought to enhance insulin secretion in the short term. This mechanism, however, is not well-understood ${ }^{2}$. GPR40, a G-protein-coupled 
receptor abundantly expressed in the pancreas, is shown to operate as a receptor for long-chain FFAs. Furthermore, we show that long-chain FFAs activate GPR40, which increases glucose-stimulated insulin release from pancreatic cells. ${ }^{41}, 42$ The presence of glucose activates an enzyme, which transforms glucose into a molecule that plays a vital part in the secretion of insulin, as illustrated in the picture that shows diagram no. (1), how insulin is produced in the presence of glucose, amino acids, flavonoids, and fatty acids. The chemical acetylcholine, on the other hand, plays a critical function in blocking fatty acid oxidation and aids in increasing fatty acid production, which promotes insulin secretion. While the chemical stimulates beta receptors in pancreatic cells, increasing insulin secretion, it also inhibits alpha receptors, lowering fatty acid oxidation and increasing insulin secretion as shown in the diagram no.(1). ${ }^{28}$

5. Anti-diabetic medications that could be developed in the future, Alpha antagonists. In the development of highly specific antagonists for the treatment of type 2 diabetes (inhibition of insulin production via the 2-receptor), Fatty acid oxidation is inhibited by an antagonist of the alpha 2-receptor and activator of glucokinase. Alpha antagonists, which are potential novel anti-diabetic medicines, have a limited therapeutic utility. The development of highly specific antagonists for the treatment of type 2 diabetes, because normal adrenaline-driven glucose release from the liver is reduced and controlled by B-receptors, the use of B-receptor antagonists worsens the caused hypoglycemia in diabetes patients. A number of medicines are now being investigated, including alpha 2 adrenoceptor tion and glucokinase activators. Because B3 adrenoceptors control lipolysis in fat cells, researchers are looking into the idea of utilizing selective B3 agonists, which are currently under development for the treatment of obesity and type 2 diabetes. ${ }^{43}, 44$

Methanol PDS treatment of diabetic rabbits resulted in a considerable improvement in the diabetic group. This impact could be explained by the good glycemic control provided by methanol extract of PDS, as evidenced by the large reduction (by $80 \%$ ) in blood glucose levels compared to the diabetics' fig (C, D) who were not treated in fig (B). In histopathology, the degeneration observed in the pancreas of dexamethasone-induced diabetic rabbits may be due to the necrotic action of dexamethasone on the beta cells fig $(B)^{45}$. The degenerative changes induced by dexamethasone in rabbit's pancreas were recovered by PDS extract and insulin fig (E) which was followed by regeneration of the islet cells and increased tissue density with attendant improved insulin production and reduction of FBG in rabbits. This effect was more pronounced at $400 \mathrm{mg} / \mathrm{kg}$ PDS extract fig (D). It has been demonstrated that beta cells can regenerate from stem cells located in pancreatic ducts or from progenitor cells residing inside islets ${ }^{46}$. Regeneration of the islet cells by PDS extract may involve the promotion of the above mechanisms. In addition, fatty acids, flavonoids are reported to regenerate the damaged pancreatic $\beta$-cells in diabetics. As a result, the presence of fatty acids, amino acids and flavonoids in $P$. dactylifera seeds may explain our findings of the antihyperglycemic effects in the diabetic rabbits induced by dexamethasone.

\section{Conclusion}

PDS and its extracts have a hypoglycemic impact in dexamethasone-induced diabetic rabbits, according to the findings of the current study. PDS and its extracts may have anti-diabetic benefits by increasing insulin secretion, stimulating glucose uptake and glycogen synthesis in cells, and/or protecting pancreatic -cells from dexamethasone- and glucose-induced oxidative stress. The presence of flavonoids and fatty acids in the methanol extract may cause this action, which is dose and duration-dependent. They operate through a variety of techniques However, more research is needed to isolate and understand the bioactive compound(s) responsible for the antihyperglycemic effect, as well as the molecular mechanism of action. As a result, Phoenix dactylifera $L$. seed's extract could be used as a supplement to insulin in order to extend the duration of action, improve the efficacy, and/or reduce the doses, lowering the risk of side effects.

\section{Declarations}

\section{Acknowledgments:}

The authors are thankful to all the staff of Al-Awlaki laboratories, Sana'a, Yemen, and the Faculty of Science Department of Plants, Sana'a University, Yemen, the Central Veterinary Laboratory in Sana'a, Yemen.

\section{References}


1. Nehdi I, Omri S, Khalil MI, Al-Resayes SI. Characteristics and chemical composition of date palm (Phoenix canariensis) seeds and seed oil. Ind Crops Prod. 2010;32(3):360-365. https://doi.org/10.1016/j.indcrop.2010.05.016.

2. Al-Farsi* MA, Lee CY. Nutritional and functional properties of dates: a review. Crit Rev Food Sci Nutr. 2008;48(10):877-887. https://doi.org/10.1080/10408390701724264

3. Al-Farsi M, Alasalvar C, Al-Abid M, Al-Shoaily K, Al-Amry M, Al-Rawahy F. Compositional and functional characteristics of dates, syrups, and their by-products. Food Chem. 2007;104(3):943-947.

https://www.researchgate.net/publication/223542522_Compositional_and_functional_characteristics_of_dates_syrups_and_their_byproducts

4. Habib HM, Ibrahim WH. Effect of date seeds on oxidative damage and antioxidant status in vivo. J Sci Food Agric. 2011;91(9):1674-1679.

5. Habib HM, Platat C, Meudec E, Cheynier V, Ibrahim WH. Polyphenolic compounds in date fruit seed (Phoenix dactylifera): characterisation and quantification by using UPLC-DAD-ESI-MS. J Sci Food Agric. 2014;94(6):1084-1089.

6. Paranthaman R, Praveen Kumar P, Kumaravel S. HPLC and HPTLC Determination of Caffeine in Raw and Roasted Date Seeds (Phoenix Dactylifera L). 1: 249. doi: 10.4172/scientificreports. 249 Page 2 of 4 Volume 1• Issue 4• 2012 thoroughly. Raw date seeds dry heated seed samples were Gr to a fine powder stored a Sep screw cap bottle. 2012;20. https://www.researchgate.net/publication/285379665.

7. El Abed H, Chakroun M, Fendri l, et al. Extraction optimization and in vitro and in vivo anti-postprandial hyperglycemia effects of inhibitor from Phoenix dactylifera L. parthenocarpic fruit. Biomed Pharmacother. 2017;88:835-843.

8. $\quad$ Organization WH. WHO Expert Committee on Diabetes Mellitus [Meeting Held in Geneva from 25 September to 1 October 1979 ]: Second Report. World Health Organization; 1980. https://apps.who.int/iris/handle/10665/41399.

9. Barik R, Jain S, Qwatra D, Joshi A, Tripathi GS, Goyal R. Antidiabetic activity of aqueous root extract of Ichnocarpus frutescens in streptozotocin-nicotinamide induced type-Il diabetes in rats. Indian J Pharmacol. 2008;40(1):19.

10. Ayeleso AO, Joseph JS, Oguntibeju OO, Mukwevho E. Evaluation of free radical scavenging capacity of methoxy containinghybrids of thiosemicarbazone-triazole and their influence on glucose transport. BMC Pharmacol Toxicol. 2018;19(1):1-10.

11. Ahmed F EF, Aly M A, Muhammad A, Raeesa A M, Amr S M, Ali H AR. Hypoglycemic effects of date seed extract. Possible mechanism of action, and potential therapeutic implications. Published online 2013.

12. Zangiabadi N, Asadi-Shekaari M, Sheibani V, et al. Date fruit extract is a neuroprotective agent in diabetic peripheral neuropathy in streptozotocin-induced diabetic rats: a multimodal analysis. Oxid Med Cell Longev. 2011;2011.

https://doi.org/10.1155/2011/976948

13. Pinchevsky Y, Butkow N, Raal FJ, Chirwa T, Rothberg A. Demographic and clinical factors associated with development of type 2 diabetes: a review of the literature. Int J Gen Med. 2020;13:121.

14. Lin $\mathrm{H}$, Teng $\mathrm{H}, \mathrm{Wu}$ W, et al. Pharmacokinetic and metabolomic analyses of Mangiferin calcium salt in rat models of type 2 diabetes and non-alcoholic fatty liver disease. BMC Pharmacol Toxicol. 2020;21(1):1-12.

15. Salib JY, Michael HN, Eskande EF. Anti-diabetic properties of flavonoid compounds isolated from Hyphaene thebaica epicarp on alloxan induced diabetic rats. Pharmacognosy Res. 2013;5(1):22.

16. Meikle PJ, Wong G, Barlow CK, et al. Plasma lipid profiling shows similar associations with prediabetes and type 2 diabetes. PLoS One. 2013;8(9):e74341.

17. O'Connell RS, Clinger BN, Donahue EE, Celi FS, Golladay GJ. Dexamethasone and postoperative hyperglycemia in diabetics undergoing elective hip or knee arthroplasty: a case control study in 238 patients. Patient Saf Surg. 2018;12(1):1-8. 
18. Marles RJ, Farnsworth NR. Antidiabetic plants and their active constituents. Phytomedicine. 1995;2(2):137-189.

19. McDonald S, Prenzler PD, Antolovich M, Robards K. Phenolic content and antioxidant activity of olive extracts. Food Chem. 2001;73(1):73-84.

20. Merck E. Dyeing Reagents for Thin Layer and Paper Chromatography. E. Merck; 1980.

21. Development $\mathrm{O}$ for EC and. Test No. 425: Acute Oral Toxicity: Up-and-down Procedure. OECD Publishing; 2008https://doi.org/10.1787/9789264071049-en. https://doi.org/10.1787/20745788.

22. Nazar CE, Echevarria GC, Lacassie HJ, Flores RA, Munoz HR. Effects on blood glucose of prophylactic dexamethasone for postoperative nausea and vomiting in diabetics and non-diabetics. Rev Med Chil. 2011;139(6):755-761.

23. Bancroft JD, Gamble M. Theory and Practice of Histological Techniques. Elsevier health sciences; 2008.

24. Alem C, Ennassir J, Benlyas M, Mbark AN, Zegzouti YF. Phytochemical compositions and antioxidant capacity of three date (Phoenix dactylifera L.) seeds varieties grown in the South East Morocco. J Saudi Soc Agric Sci. 2017;16(4):350-357.

25. Adeosun AM, Oni SO, Ighodaro OM, Durosinlorun $\mathrm{OH}$, Oyedele OM. Phytochemical, minerals and free radical scavenging profiles of Phoenix dactilyfera L. seed extract. J Taibah Univ Med Sci. 2016;11(1):1-6.

26. Abdelmalak BB, Bonilla AM, Yang D, et al. The hyperglycemic response to major noncardiac surgery and the added effect of steroid administration in patients with and without diabetes. Anesth Analg. 2013;116(5):1116-1122.

27. Sivabalan S, Renuka S, Menon VP. Fat feeding potentiates the diabetogenic effect of dexamethasone in Wistar rats. Int Arch Med. 2008;1(1):1-12.

28. McGarry JD, Dobbins RL. Fatty acids, lipotoxicity and insulin secretion. Diabetologia. 1999;42(2):128-138.

29. Ibrahim KM, Al-Shawi NN, Al-Juboury RA. A Study on the Hypoglycemic Effect of Ficus carica L. Leaves Aqueous Extract against Alloxan-Induced Diabetes in Rabbits. Med J Babylon. 2009;6(3-4).

30. Rauter AP, Martins A, Lopes R, et al. Bioactivity studies and chemical profile of the antidiabetic plant Genista tenera. $J$ Ethnopharmacol. 2009;122(2):384-393.

31. Wang HX, Ng TB. Natural products with hypoglycemic, hypotensive, hypocholesterolemic, antiatherosclerotic and antithrombotic activities. Life Sci. 1999;65(25):2663-2677.

32. Al-Qattan K, Thomson M, Ali M. Garlic (Allium sativum) and ginger (Zingiber officinale) attenuate structural nephropathy progression in streptozotocin-induced diabetic rats. E Spen Eur E J Clin Nutr Metab. 2008;3(2):e62-e71.

33. Kawabata J, Mizuhata K, Sato E, Nishioka T, Aoyama Y, Kasai T. 6-Hydroxyflavonoids as a-glucosidase inhibitors from marjoram (Origanum majorana) leaves. Biosci Biotechnol Biochem. 2003;67(2):445-447.

34. Andrade-Cetto A, Wiedenfeld H. Hypoglycemic effect of Cecropia obtusifolia on streptozotocin diabetic rats. $J$ Ethnopharmacol. 2001;78(2-3):145-149.

35. Matsuda H, Murakami T, Yashiro K, Yamahara J, Yoshikawa M. Antidiabetic principles of natural medicines. IV. Aldose reductase and a-glucosidase inhibitors from the roots of Salacia oblonga Wall.(Celastraceae): structure of a new friedelane-type triterpene, kotalagenin 16-acetate. Chem Pharm Bull. 1999;47(12):1725-1729.

36. Narváez-Mastache JM, Garduño-Ramírez ML, Alvarez L, Delgado G. Antihyperglycemic activity and chemical constituents of Eysenhardtia platycarpa. J Nat Prod. 2006;69(12):1687-1691.

37. Kim HY, Moon BH, Lee HJ, Choi DH. Flavonol glycosides from the leaves of Eucommia ulmoides O. with glycation inhibitory activity. J Ethnopharmacol. 2004;93(2-3):227-230. 
38. Gu H-J, Lv J-C, Yong K-L, Chen X, Liu P-P, Zhang X-B. Antidiabetic effect of an active fraction extracted from dragon's blood (Dracaena cochinchinensis). J Enzyme Inhib Med Chem. 2009;24(1):136-139.

39. Dobler CC, Flack JR, Marks GB. Risk of tuberculosis among people with diabetes mellitus: an Australian nationwide cohort study. BMJ Open. 2012;2(1):e000666.

40. Burnie G, Forrester S, Greig D, Guest S. Botanica: Encyclopédie de botanique et d'horticulture. Menges, Paris. Published online 2006.

41. Bergman RN, Ader M. Free fatty acids and pathogenesis of type 2 diabetes mellitus. Trends Endocrinol Metab. 2000;11(9):351356.

42. Humphrey PR, Maureen MD, Ritter JM. Rang \& Dale's Pharmacology. Elsevier; 2012. http://www.worldcat.org/oclc/840366762

43. Ritter J, Flower RJ, Henderson G, Loke YK, MacEwan DJ, Rang HP. Rang and Dale's pharmacology. Published online 2019. http://www.worldcat.org/oclc/1099547065.

44. Katzung Bertram G, Trevor Anthony J. Basic and Clinical Pharmacology 13 E: Bertram G. Katzung. Published online 2015. http://www.worldcat.org/oclc/921871197

45. Yasir M, Das S, Kharya MD. The phytochemical and pharmacological profile of Persea americana Mill. Pharmacogn Rev. 2010;4(7):77.

46. Liu H, Guz Y, Kedees MH, Winkler J, Teitelman G. Precursor cells in mouse islets generate new $\beta$-cells in vivo during aging and after islet injury. Endocrinology. 2010;151(2):520-528.

\section{Tables}

Tables 1 - 3 are available in the supplementary files section.

\section{Figures}




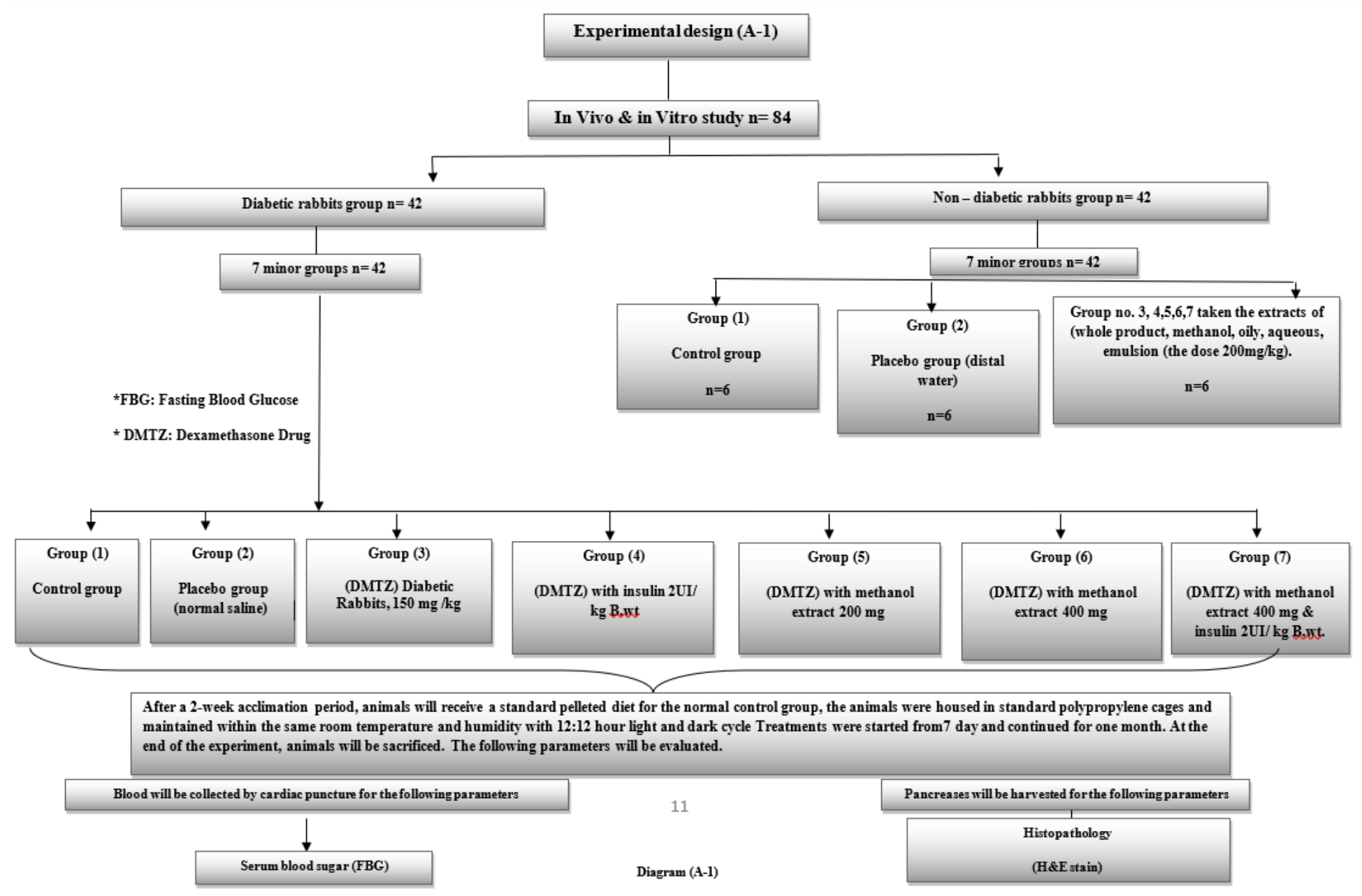

Figure 1

Diagram A-1. Legend not available with this version.

Figure 2

Diagram 1. Legend not available with this version.

\section{Figure 3}

Figure 1 legend not available with this version.

\section{Supplementary Files}

This is a list of supplementary files associated with this preprint. Click to download.

- Tables.docx 